\title{
EIDIA
}

Revista Eletrônica de Estudos Integrados em Discurso e Argumentação

dx.doi.org/10.17648/eidea-16-2224

\section{REDES SOCIAIS E POLÍTICA NA ARGENTINA}

\author{
Natalia Aruguete ${ }^{i}$ \\ Ernesto Calvoii
}

Resumo: Ativistas, políticos e organizações sociais têm a capacidade de transmitir opiniões e promover a desobediência civil, ignorando as rotas de informação delineadas por jornalistas e meios de comunicação tradicionais. Essa tensão colocada na definição de agendas convencionais representa um desafio para as hipóteses dos modelos de comunicação estudados. Este artigo reflete sobre as relações políticas e sociais que se refletem na rede do Twitter, onde a conversa virtual promove polarização política, consolida hierarquias da mídia, estabelece um diálogo único entre as agendas políticas, midiáticas e públicas, e fortalece a concentração de conteúdo gerado por usuários de alto escalão, cujo prestígio político, social, econômico e cultural não se altera com seu ingresso às redes.

Palavras-chave: Twitter . Polarización política. Concentración mediática. Agendas

\begin{abstract}
Activists, politicians and social organizations have the ability to convey opinions and promote civil disobedience by skipping the information routes outlined by journalists and traditional media. This tension placed on the definition of conventional agendas poses a challenge to the hypotheses of the communication models studied. This article reflects on the political and social relationships that are reflected in the Twitter network, where the virtual conversation promotes political polarization, consolidates media hierarchies, establishes a unique dialogue between the political, media and public agendas, and strengthens the concentration of content generated by high-ranking users, whose political, social, economic and cultural prestige is not altered by their entry into the networks.
\end{abstract}

Keywords: Twitter. Political polarization. Media concentration. Agendas.

\footnotetext{
' Docente da Universidade Nacional de Quilmes (UNQ) e pesquisadora do Conselho Nacional de Investigações Científicas e Técnicas (CONICET), Argentina. Email: nataliaaruguete@gmail.com.

ii Docente da Universidade de Maryland (UM), Estados Unidos da América.

E-mail: ecalvo@umd.edu.
} 
EID\&A - Revista Eletrônica de Estudos Integrados em Discurso e Argumentação, Ilhéus, n. 16 esp. "Discurso e argumentação na política latino-americana, set.2018.

\section{Redes sociais e polarização política}

O Twitter convida à convivência múltiplos atores da política diária: os partidos políticos e seus candidatos, os funcionários público, os grupos de interesse, os meios massivos de comunicação e seus jornalistas e o "baixo povo". Mas longe de prometer uma esperança renovada de pluralismo comunicacional, os transeuntes virtuais são uma "minoria auto-selecionada" (BARBERÁ, 2015, p. 26). E ainda que não possamos acessar toda a informação que circula pela rede, é possível traçar preferências ideológicas e proximidades políticas pelo seu posicionamento na "tuitosfera" (BOUTET et al., 2012).

As recentes comoções públicas na Argentina consolidaram a polarização nas ruas e, com maior virulência, no diálogo virtual: \#Nisman no contexto eleitoral de 2015, \#RuidazoContraEITarifazo, por volta de 2016 e \#Maldonado durante as eleições legislativas de 2017. A polarização política e social no Twitter pode ser analisada a partir de duas perspectivas: uma macro e uma micro.

A partir de uma perspectiva macro, a segregação informativa delimita regiões que se fecham em si mesmas e nas quais os indivíduos têm à sua disposição uma oferta de mensagens que se ajustam às suas preferências, descrevem seus pontos de vista e são consistentes com "seu mundo da vida"1. Por isso, quanto mais intensas forem as conexões dentro de uma comunidade, maior será a segregação das narrativas a que se expõem seus membros. O Twitter atua como uma câmara de eco. "Lo que sale de una cámara de eco guarda una relación inevitable e invariable con lo que entra en ella" (KEY \& CUMMINGS, 1966, p. 2). Somos o que expomos em nosso perfil virtual, nos conhecem pelo tipo de mensagem que difundimos. Com esses rastros, os administradores eletrônicos organizam um uma distribuição seletiva do conteúdo que cada um verá em seu "mural", consolidando as "bolhas" de informação. Parisier (2017) propõe a noção de "bolhas de filtros" (filter bubble) para se referir ao papel que desempenham as redes sociais em nossas decisões, ao nos mostrar algumas possibilidades, ocultar outras e, assim, “moldar" em quem nos convertemos (PARISIER, 2017, p. 116).

\footnotetext{
${ }^{1}$ Habermas define o mundo da vida como "el lugar trascendental en que hablante y oyente salen al encuentro; en que pueden plantearse recíprocamente la pretensión de que sus emisiones concuerdan con el mundo (con el mundo objetivo, con el mundo subjetivo y con el mundo social)" (HABERMAS, 2002, p. 179).
} 
EID\&A - Revista Eletrônica de Estudos Integrados em Discurso e Argumentação, Ilhéus, n. 16 esp. "Discurso e argumentação na política latino-americana, set.2018.

A resposta micro dos cidadãos virtuais consistem em atribuir posições partidárias às entidades de meios de comunicação, filtrar o conteúdo em função da congruência ideológica percebida (BENNETT \& IYENGAR, 2008), e propagá-lo em forma coerente com suas crenças e valores, selando a fogo as bolhas de informação. Dessa forma, dialogamos e fundimos nossas agendas com as daqueles usuários que passeiam pelos nossos mesmos bairros. Essas variáveis de corte cognitivo, expressadas por Bennett e lyengar (2008) condizem com a ideia de percepção seletiva. Lazarsfeld, Berelson e Gaudet (1944) corroboram a hipótese das mínimas consequências, segundo a qual a exposição aos meios de comunicação solidificam preferências, cristalizam e reforçam mais que convertem. [...]. A cristalização e o reforço se confirmam mutuamente. Reforçar é consolidar atitudes e opiniões existentes, cristalizar é dar forma a uma vaga preferência prévia. Nesses termos, a busca de certas mensagens facilita "o apoio social para respaldar uma postura já assumida" (McCOMBS, 1993, p. 97).

No interior das comunidades, nos encontramos com uma grande quantidade de evidências que reforçam nossos preconceitos e que, ao mesmo tempo, desarticulam as "mentiras" dos usuários das comunidades opostas. 0 aumento do intercâmbio, por meio de retuítes, respostas, likes e comentários, confirma a validade dos algoritmos que recomendam a quem seguir ou qual tuíte olhar e "informam" acerca das tendências (CALVO, 2015). A convergência dessas duas dinâmicas - macro e micro - cristaliza a endogamia nas redes e polariza politicamente sua geografia, distribuindo os usuários em regiões bem definidas que intercambiam informação quase exclusivamente com aqueles que compartilham ideias e esquemas de percepção.

Não é fácil ser oficialista no Twitter em meio a uma crise política. Não é agora e nem foi para o governo anterior. Isso explica, em parte, que a propagação de mensagens no interior do polo que aglutina os usuários opostos às ideias do governo quase duplique a circulação na comunidade que comunga com a palavra oficial, tanto pela quantidade como pelo ritmo de ações de retuitar. Tratam-se de regiões que enquadram suas mensagens com narrativas contrapostas.

Dois acontecimentos recentes na Argentina são eloquentes para representar a polarização política no Twitter. Em meados do ano de 2016, parte importante da sociedade argentina encheu esquinas e praças, mobilizada por um \#Ruidazo contra o aumento desmesurado das tarifas dos 
EID\&A - Revista Eletrônica de Estudos Integrados em Discurso e Argumentação, Ilhéus, n. 16 esp. "Discurso e argumentação na política latino-americana, set.2018.

serviços públicos. Tamanhas manifestações conseguiram que o governo de Mauricio Macri revisasse seus cálculos, ainda que a questão de fundo seguisse sem resolução, de forma que, as demandas judiciais pela falta de razoabilidade dos aumentos são contínuas. Aquelas manifestações de 2016 foram impulsionadas fundamentalmente pelas redes sociais, sempre prontas para coordenar a mobilização de diversos atores. Os mais de 600 mil tuítes angariados nos dias anteriores e posteriores ao \#Ruidazo, assim como os colhidos imediatamente antes e depois da decisão da Corte Suprema de Justicia de la Nación (CSJN) do 18 de agosto, transitaram por regiões separadas que não interagiram entre si. Opositores e oficialistas reagiram e justificaram a medida mediante seus likes e seus retuítes. Com uma tematização densa \#Ruidazo \#Tarifazo \#Recalculando \#MacriVergüenzaNacional \#Cacerolazo y \#CorrupciónK, entre outros hashtags - a rede \#Tarifazo delimitou um cenário polarizado.

\section{Gráfico 1 - Polarização na rede \#Tarifazo}

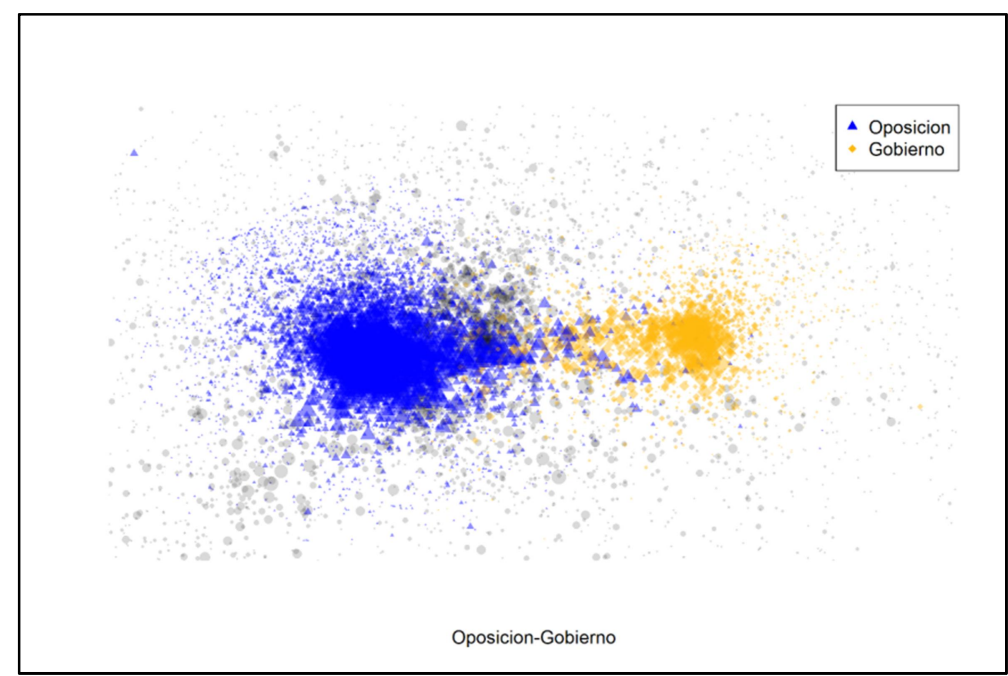

A comunidade da oposição com triângulos azuis (23.905 nós), a comunidade governista com diamantes de ouro (10,133 nós) e os usuários não afiliados como pontos cinzas (19,416 nós). A intensidade do intercâmbio na comunidade da oposição quase duplica a da comunidade governista.

Fonte: Elaboração própria.

A polarização fervente e os fogos cruzados, impulsionados em parte por uma dinâmica de call center, alcançou seu ponto culminante no marco da disputa narrativa ao redor da desaparição forçada e da posterior morte de Santiago Maldonado. A três meses da repressão da Gendarmería na "ruta 40" (localizada no departamento de Cushamen, província de Chubut), onde 
EID\&A - Revista Eletrônica de Estudos Integrados em Discurso e Argumentação, Ilhéus, n. 16 esp. "Discurso e argumentação na política latino-americana, set.2018.

Santiago foi visto pela última vez, os mais de 7.5 milhões de tuítes que circularam no caso \#Maldonado mantiveram as intrigas entre os usuários que habitam as regiões opositoras e oficialistas.

\section{Gráfico 2 - Polarização na rede \#Maldonado}

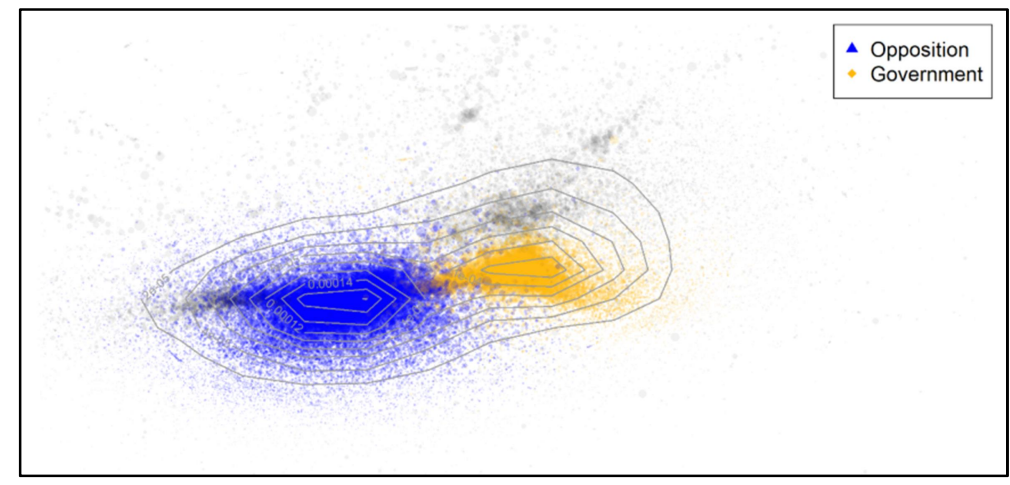

A comunidade da oposição com pontos azuis (101,583 nós), a comunidade governista com pontos amarelos (51,033 nós).

Fonte: Elaboração própria.

\section{Hierarquia e concentração}

A emergência das redes sociais permite a produção e circulação de conteúdos gerados pelo usuário quase em tempo real, em uma cultura comunicacional crescentemente interativa: produtores e consumidores de informação pareceram fundir-se em um diálogo de tipo "gatewatching", em que o "productor ciber-urbano" participa na criação de espaços online, reeditando, filtrando e recriando o conteúdo dos meios de comunicação (Bruns, 2008). Nesse sentido, acreditamos ser necessário refletir acerca do conceito de participação e de interatividade. Compreende-se a interatividade a partir de (i) uma perspectiva técnica dos sistemas de meios (MANOVICH, 2001), de (ii) um ponto de vista social e como experiência humana marcada pelo uso de tais sistemas (KIOUSIS, 2002), (iii) a partir das dinâmicas do poder que estruturam o acesso à comunicação (SCHULTZ, 2000) ou, incluso, (iv)a partir de um conceito político vinculado às oportunidades concretas do governamentalismo e da cidadania em uma dada sociedade (GANE \& BEER, 2008). Um intercâmbio intenso no Twitter costuma coincidir com um alto grau de concentração das mensagens relevantes e uma hierarquia consolidada de

\footnotetext{
${ }^{2}$ Bruns (2008) reconceitualiza o termo "gatekeeping" e o define como "gatewatching", aludindo à capacidade do consumidor de reeditar, voltar a filtrar e recriar o conteúdo dos meios.
} 
EID\&A - Revista Eletrônica de Estudos Integrados em Discurso e Argumentação, Ilhéus, n. 16 esp. "Discurso e argumentação na política latino-americana, set.2018.

certos atores institucionais, em que os políticos, as figuras midiáticas e os meios tradicionais dominam a atividade. $O$ sonho da democracia direta morreu a partir do momento em que nós, usuários, optamos por citar e retuitar as velhas instituições como fontes primárias de informação, em lugar de nos seguirmos ou retuitarmos uns aos outros. Por isso, ainda que este artigo não enfoque um debate sobre as noções de participação e de interatividade, advertimos que a atual afluência de mensagens virtuais, assim como a capacidade de consumir e recriar a informação, quase ao mesmo tempo em que esta se produz, não garante por si o fluxo democrático e participativo da informação.

\section{Gráfico 3 - Autoridades na comunidade da oposição (azul) e na comunidade do governo (amarelo) na rede \#Maldonado, período 2 de agosto a 19 de outubro de 2017}
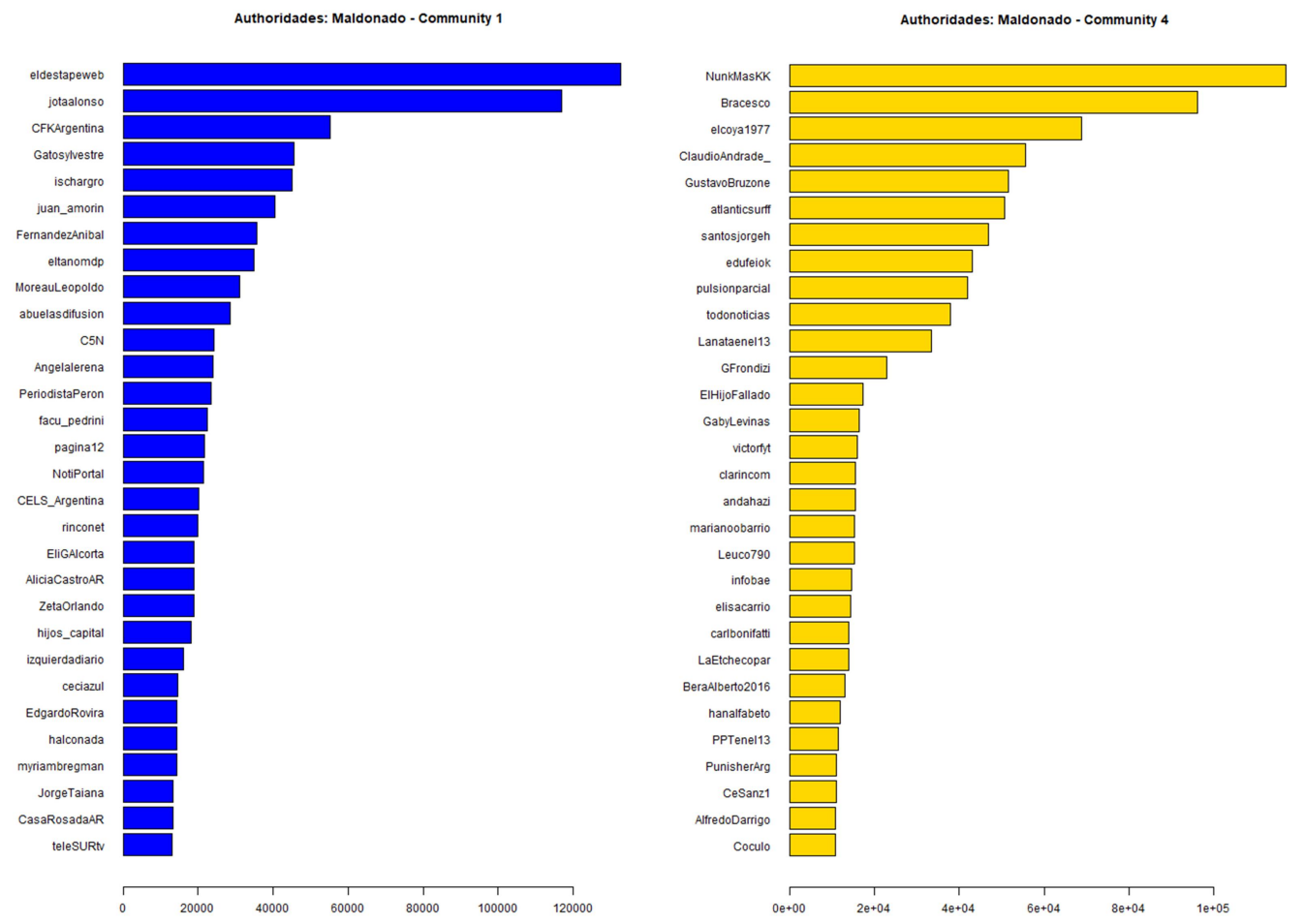

A comunidade da oposição - com barras azuis - tem entre suas autoridades dirigentes políticos, jornalistas influentes e meios de comunicação. Entre as principais autoridades da comunidade governista - com barras amarelas-, há uma forte presença de contas falsas.

Fonte: Elaboração própria.

Um dos motivos pelos quais a informação de referentes midiáticos e políticos tende a circular mais extensamente pela rede, é que o que se publica 
EID\&A - Revista Eletrônica de Estudos Integrados em Discurso e Argumentação, Ilhéus, n. 16 esp. "Discurso e argumentação na política latino-americana, set.2018.

tem consequências políticas. As autoridades das redes ${ }^{3}$ são as que também afetam nossas vidas no mundo não-virtual. Definimos as autoridades como aqueles usuários que têm muitos seguidores; os políticos, da mesma forma que as grandes empresas e as celebridades, preferem ser seguidos por muitos e seguir poucos.

A saturação e a homogeneidade monopolizadas pelos meios tradicionais não reduzem os níveis de polarização na rede Twitter, ainda que a intensidade da conversa no interior das comunidades mostre características singulares. Enquanto os atores mais ativos da oposição na rede \#Maldonado são figuras políticas como@CFKArgentina, @FernandezAnibal e @MoreauLeopoldo, a linha de frente do Governo fica nas mãos de "jornalistas de guerra" ou fakes, como@NuncaMask, @Bracesco e @elcoya77 (CALVO, 2017).

\section{Fundindo agendas}

A influência midiática convencional já não tem apoio no novo ecossistema, em que o surgimento de plataformas interativas convive com as dificuldades econômicas e financeiras que atravessam os meios tradicionais, infligidos em sua capacidade de demarcar a opinião do público de maneira generalizada e homogênea. Neste interregno, a pergunta que subjaz é se as redes sociais logram forjar uma agenda alternativa ou se repetem as pautas propostas pelos meios de elite. E, uma vez mais, os caminhos se bifurcam: são um desafio real para os padrões tradicionais do jornalismo ou, em contrapartida, uma ferramenta de normalização ${ }^{4}$ Depende.

Nem todas as notícias têm um leitor. Nos meios tradicionais existem brechas entre a instância de produção e a do consumo da informação (ALTHAUS, CIZMAR, \& GIMPEL, 2009; BOCZKOWSKI, MITCHELSTEIN, \& MATASSI, 2017). No cenário virtual, ativistas, políticos e organizadores sociais têm a capacidade de transmitir opiniões e promover desobediências civis, transpondo os caminhos da informação delineados pelos meios tradicionais. $O$

\footnotetext{
${ }^{3}$ Como definimos graficamente a relação entre autoridades e seguires? As redes são diagramas integrados por nós e conectores. A nodalidade é a ação de seguir a outros. A flecha que sai do nó que chamamos "seguidor" é recebida pelo nó "autoridade" (S_retw ? A_tw). As flechas a partir dos seguires até às autoridades mostram quem se comunicá assiduamente e quem tem um contato marginal ou nulo e, com isso, evidenciam que o fluxo desses discursos é profundamente assimétrico (ARUGUETE \& CALVO, 2017).

4 Os pesquisadores Singer (2005) e Lasorsa, Lewis e Holton (2012) aludem ao termo "normalização" para se referirem ao uso que os jornalistas fazem dos meios sociais como uma ferramenta "padronizadora" das normais e das práticas tradicionais do jornalismo.
} 
EID\&A - Revista Eletrônica de Estudos Integrados em Discurso e Argumentação, Ilhéus, n. 16 esp. "Discurso e argumentação na política latino-americana, set.2018.

comportamento em linha - o "gostar" e o "compartilhar" - expõe rapidamente aos usuários da rede a informação de maneira fragmentada e heterogênea (WEBSTER \& KSIAZEK, 2012). Poderiam as novas tecnologias, que permitem aos usuários assinalar rapidamente suas preferências sobre aquilo que desejam ler e difundir, significar uma volta à era dos efeitos mínimos? (BENNETT \& IYENGAR, 2008). A pergunta é válida se assumimos que as instituições midiáticas não apenas são incapazes de transformar a mente de suas audiências ou pender o voto dos indecisos, mas também não conseguem fixar a agenda pública de maneira monolítica e unidirecional (HALL \& ARTWICK, 2012), a menos que tentem fazê-lo intersticialmente.

Com a intenção de superar a relação unicausal entre os meios massivos e públicos, Shaw e seus colegas propõem uma nova dinâmica. A agenda melding (fusão de agendas) assume que os indivíduos se veem motivados a se unirem a comunidades com as que compartilham interesses e valores, a filiarem-se a organizações ou a pertencerem a coletivos sociais para evitar o dilema de viver com o "ilhamento" intelectual. Assim, as pessoas fundem suas agendas com as de seus pares e permitem que a congruência social e cognitiva facilite o estabelecimento de agenda (SHAW, MCCOMBS, WEAVER, \& HAMM, 1999).

A agenda melding se nutre da noção de "dissonância cognitiva" (FESTINGER, 1962). Os indivíduos, afirma Festinger, evitam informações incômodas que ponham em jogo seus valores ou atitudes; por outro lado, buscam conteúdos que apoiem sua cosmovisão. O certo é que para pertencer a um determinado grupo é necessário buscar e conhecer os diversos níveis de agenda que convivem em seu interior, veiculados por meio de leis, regras, comunicação direta e coberturas de notícias (ARUGUETE, 2017). Bennett e lyengar (2008) sugerem ir além da formação de agendas coletivas que permitam enfrentar a ambiguidade em um mundo complexo e interconectado. Da mesma forma Chaffee e Metzger (2001) reclamam novos modelos de comunicação para compreender como os indivíduos se relacionam seletivamente com a informação e votam por temas ou aspectos que coincidem com seus interesses, no interior das comunidades.

No Twitter, o usuário dedica mais tempo a compartilhar informação do que a criar conteúdos novos. Por isso, na medida em que os usuários usem e retuitem mensagens, seus companheiros ficarão expostos a um determinado conteúdo multimídia. Uma forma de indagar a consistência cognitiva entre os meios tradicionais e os que circulam na rede é observar o tipo de fontes 
EID\&A - Revista Eletrônica de Estudos Integrados em Discurso e Argumentação, Ilhéus, n. 16 esp. "Discurso e argumentação na política latino-americana, set.2018.

incorporadas nos links compartilhadas pelos usuários. Na rede \#Tarifazo, observamos que $29,9 \%$ dos tuítes incluem links que redirecionam os usuários à publicações que já estão em circulação na web: no Twitter, no Facebook e no Instagram, em nichos políticos e empresariais e em jornais tradicionais como La Nación, Clarín, Ámbito Financiero y Página/12. O hiperlink mais incluído nas postagens analisadas provêm do Twitter, ainda que seus conteúdos mostrem uma alta heterogeneidade narrativa. O segundo link que aparece com mais frequência dentro das mensagens governistas redirecionam ao diário $L a$ Nación e ao canal por assinatura Todo Noticias. Na região dos opositores, os principais hiperlinks pertencem a meios relativamente marginais, como Mundo Empresarial y El Destape Web.

O ilusório surgimento de uma narrativa "desde abaixo" vivida durante o primeiro mês a partir da desaparição de Maldonado no dia $1^{\circ}$ de agosto de 2017, em que os votantes aumentaram a intensidade do diálogo virtual e impuseram suas preferências mediante um ataque informativo - "Soy (nombre) y estoy en (lugar); lo que no sé es dónde está Santiago Maldonado" -, se consolidou com uma tematização dos acontecimentos no âmbito institucional, apropriada pelos meios de comunicação comunitários, populares e alternativos. Com o passar dos dias, a massificação da informação focalizada nos acontecimentos espetaculares é acompanhada por um enquadramento oficial que nega a desaparição, atribui a responsabilidade dos ocorridos à comunidade mapuche e reivindica o acionamento da Gendarmería. "Esta redefinición de la situación vulnera el discurso - construido en las redes sociales y en las coberturas de los medios alternativos - que había logrado instalarse como legítimo" (ISAÍA \& ARUGUETE, 2017). Coerente com esse comportamento midiático, a inclusão de links dos meios tradicionais nas postagens dos usuários, bem como sua difusão mediante retuítes, segue a evolução narrativa que descrevemos aqui. Clarín inicia o período com um nível reduzido de links incorporados pelos usuários da comunidade do governo e dá um salto até fins de agosto, superando a quantidade de hiperlinks que redirecionam para Página/12 nas postagens dos vizinhos do bairro dos opositores. 
EID\&A - Revista Eletrônica de Estudos Integrados em Discurso e Argumentação, Ilhéus, n. 16 esp. "Discurso e argumentação na política latino-americana, set.2018.

\section{Gráfico 4 - Links de meios tradicionais incorporadas na rede \#Maldonado, entre 2 de agosto e 19 de outubro}

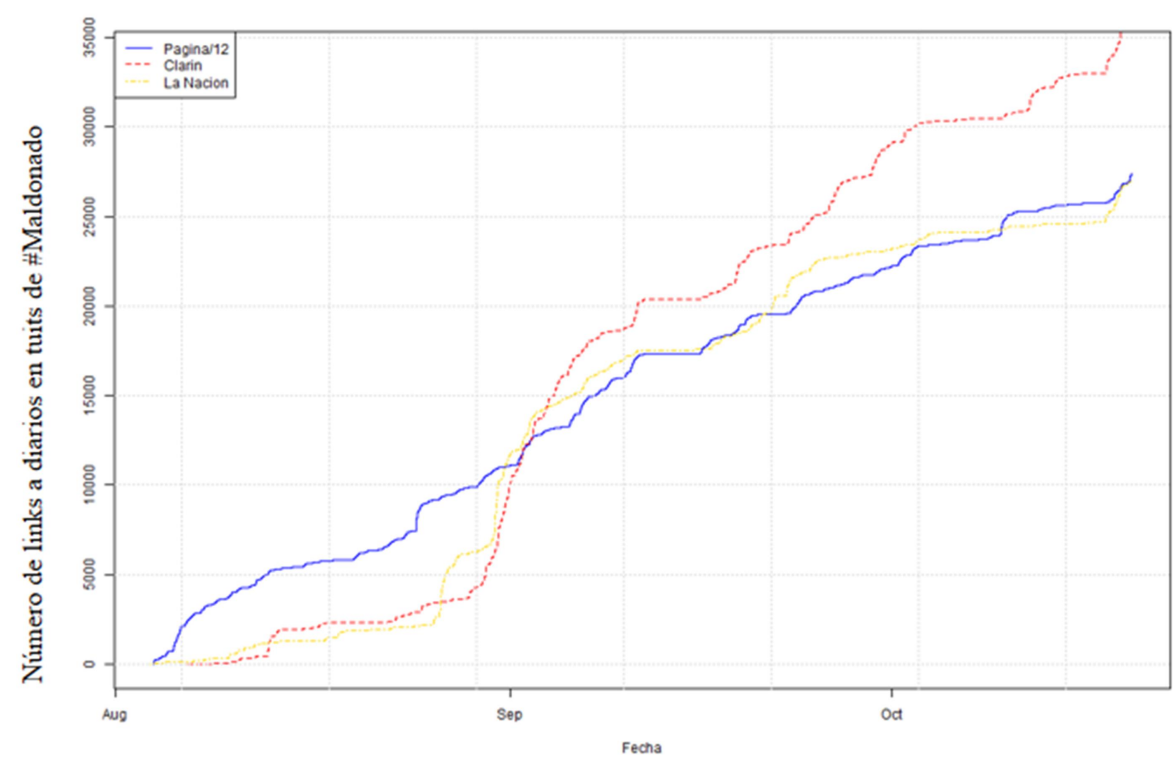

Número de tuítes do governo e da oposição no caso Maldonado, sobre uma mostra de 599,762 tuítes capturados no período de 2 de agosto a 19 de outubro.

Fonte: Elaboração própria.

A dissonância cognitiva se constata mais ainda se considerarmos o tempo que gasta um usuário para retuitar a informação de seu vizinho comunitário. Ao fragmentar o diálogo na rede e nos focarmos em certas tags ou palavras chave, vemos como a velocidade de reação varia entre os distintos usuários segundo sua localização no mapa. Novamente, \#Tarifazo e \#Maldonado mostram evidências disso. No primeiro caso, os moradores da comunidade governista retuitam mais rápido publicações de meios tradicionais que incluam termos como "racionalidade", "mercados", "cuidado", "poupanças"; e tempos mais lentos para termos como "crise, "ajuste", "pobreza" e "corrupção". A oposição, por outro lado, é mais veloz para retuitar palavras chave como "excessos", "soberania", "doação", "Clarín", "Cristina", "verdade". No entanto, o tempo de retuíte desacelera frente a "preço", "pobreza”, "dano", "dívida” e "corrupção".

Se colocamos o foco em certas tags do diálogo sobre \#SantiagoMaldonado, vemos como a congruência social e cognitiva se consolidam, facilitando a conformação de uma agenda comum e aprofundando a polarização entre comunidades. 
EID\&A - Revista Eletrônica de Estudos Integrados em Discurso e Argumentação, Ilhéus, n. 16 esp. "Discurso e argumentação na política latino-americana, set.2018.

\section{Gráfico 5 - Áreas de ativação do caso \#Maldonado}
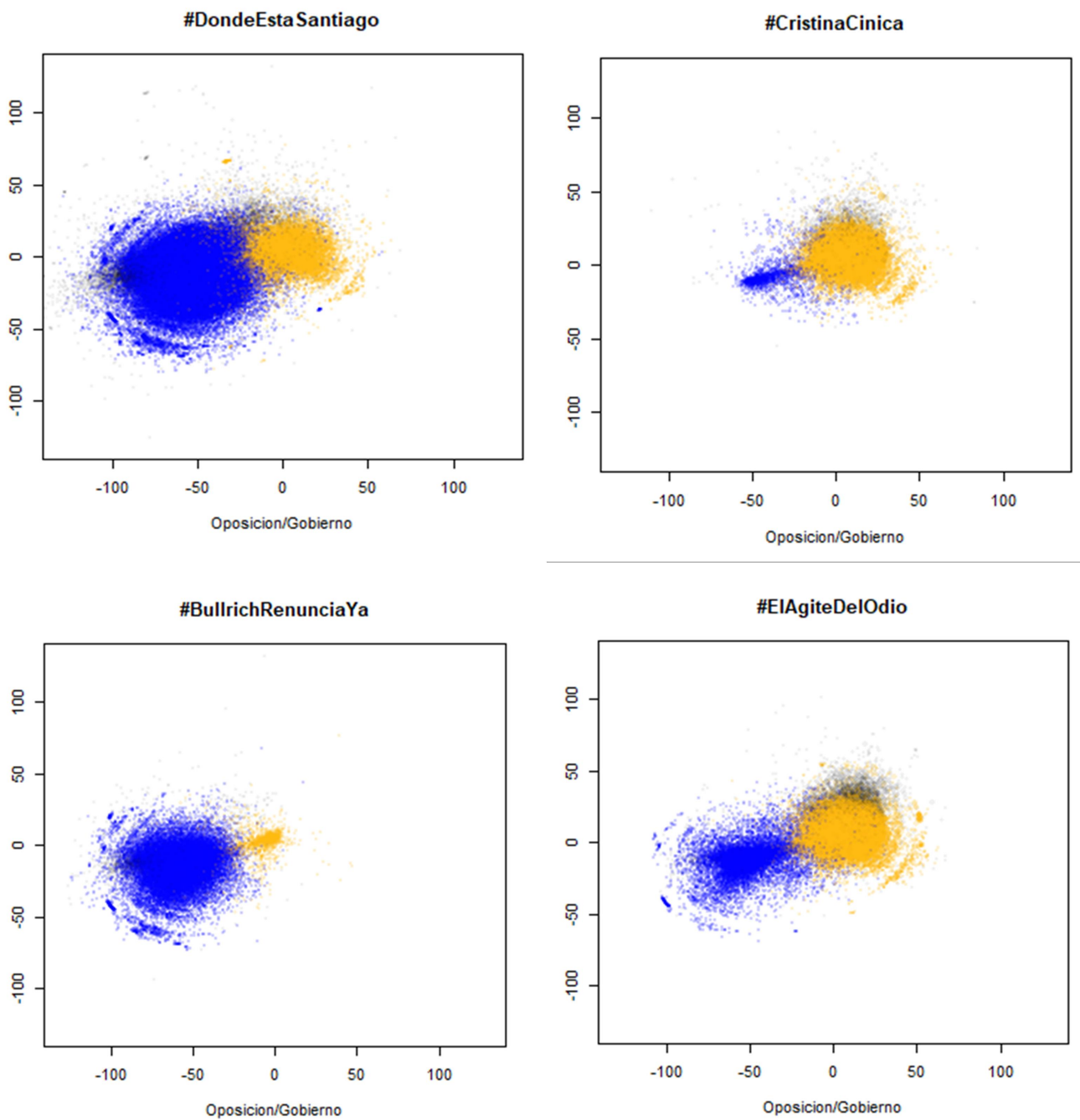

A comunidade a fim do governo, em amarelo, e a comunidade opositora, em azul. Rede estimada analisando 4,5 milhões de retuítes entre 2 de agosto e 19 de outubro. As hashtags \#CristinaCinica e \#ElAgiteDelOdio tiveram uma significativa circulação na comunidade governista enquanto que \#DondeEstaSantiago e \#BullrichRenunciaYa alcançaram uma alta propagação na comunidade opositora.

Fonte: Elaboração própria.

O mesmo ocorre quando medimos o tempo de sobrevivência ${ }^{5}$ de mensagens que incluem links de meios tradicionais. Assim, os usuários da comunidade governista mostram tempos mais curtos para retuitar as mensagens que incorporam meios amigáveis como Perfil, TN, La Nación e

\footnotetext{
${ }^{5}$ Definimos "tempo de sobrevivência" ou "latência" como o tempo que demora um tuíte original em ser retuítado. A literatura sobre processamento da informação (on-line processing) indica que os tempos de sobrevivência de uma mensagem costumam estar associados à dissonância cognitiva que estas geram (BIZER, TORMALA, RUCKER \& PETTY, 2006)
} 
EID\&A - Revista Eletrônica de Estudos Integrados em Discurso e Argumentação, Ilhéus, n. 16 esp. "Discurso e argumentação na política latino-americana, set.2018.

Clarín. Pelo contrário, os opositores têm uma forte propensão a retuitar informação que inclui meios independentes como Mundo Empresarial e La Izquierda Diario, assim como meios de comunicação consistentes com suas ideias, como Ámbito Financiero ${ }^{6}$. O gráfico seguinte evidencia que os usuários no Twitter aceitam aquelas mensagens que são cognitivamente consistentes. Ali vemos que, na comparação com o tempo de retuíte médio da rede \#Tarifazo, os usuários da comunidade governista retuitam mais rapidamente aquelas mensagens que contêm hiperlinks do diário La Nación.

\section{Gráfico 6 - Tempo de sobrevivência de retuíte nas comunidades quando incorporam La Nación}

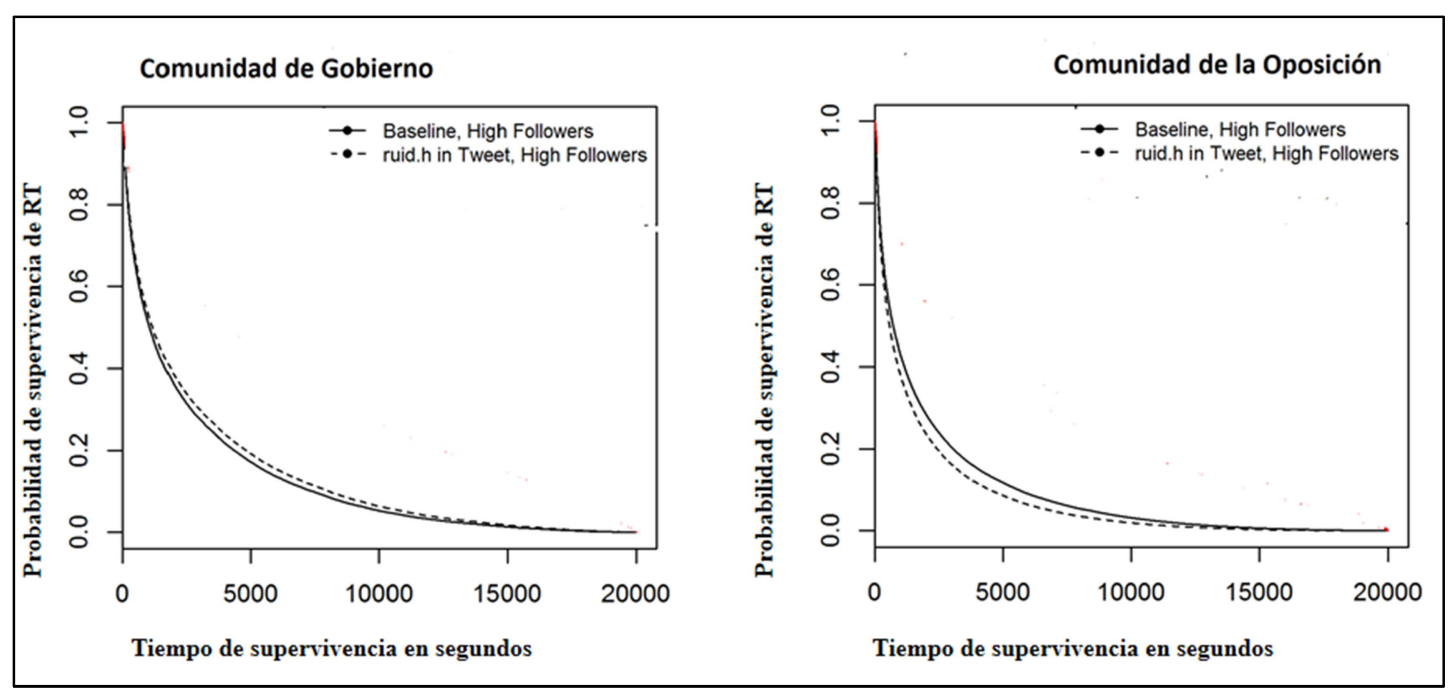

Na comunidade governista - à esquerda - as linhas pontilhadas mostram que a velocidade do retuíte é mais veloz que o tempo de sobrevivência média. Por outro lado, na comunidade opositora - à direita - os usuários retuitam mais lentamente as mensagens que incluem hiperlinks a La Nación.

Fonte: Elaboração própria.

\section{Considerações finais}

Os meios sociais oferecem a seus públicos uma maior capacidade de "ilhar-se" dentro de perspectivas alternativas e, consequentemente, contribuem na criação de agendas midiáticas heterogêneas (BAUM \& GROELING, 2008). Nessa paisagem midiática, a "creciente habilidad de los

6 Curiosamente, a estimativa de Página/12 entre os usuários da oposição é quase zero e estatísticamente insignificante. Em definitiva, enquanto os usuários incorporam meios que estão alinhados com suas próprias comunidades, o tempo de retuíte está abaixo das expectativas para Página/12 entre os usuários da oposição. 
EID\&A - Revista Eletrônica de Estudos Integrados em Discurso e Argumentação, Ilhéus, n. 16 esp. "Discurso e argumentação na política latino-americana, set.2018.

individuos de promover una percepción selectiva" é a ameaça por excelência da viabilidade da teoria da Agenda Setting (KUSHIN, 2010, p. 128).

A existência de bolhas de informação e a formação de redes parecem indicar que os indivíduos não apenas processam as mensagens guiados por suas prioridades ideológicas e seus interesses conscientes, mas também indicam que formam vínculos com seus pares em rede movidos por algoritmos que funcionam em nível estrutural (BARBERÁ, JOST, NAGLER, TUCKER \& BONNEAU, 2015). Os algoritmos selecionam uma quantidade limitada de tuítes e os distribuem entre os usuários de acordo com os rastros que esses deixam em seu percurso pelas redes: suas postagens, seus likes e seus retuítes falam da atenção seletiva destinada às diferentes narrativas.

Nas redes sociais, o ato de curtir e compartilhar expõe a um maior número de pessoas o conteúdo preferido de seus amigos. Como na câmara de eco, os usuários do Twitter preferem seguir aos políticos - ou a outras figuras de relevância - cuja posição na dimensão ideológica latente é similar à sua própria (BARBERÁ, 2015). Dessa forma, dialogam e fundem suas agendas com as daqueles usuários que passeiam pelas mesmas regiões.

\section{Referências}

ALTHAUS, Scott L.; CIZMAR, Ane M.; GIMPEL, James G. Media supply, audience demand, and the geography of news consumption in the United States. Political Communication, v. 26, n. 3, p.249-277, 2009.

ARUGUETE, Natalia; CALVO, Ernesto. \#TarifazoEnArgentina. Agenda melding y difusion de mensajes en medios sociales. In: LABATE, C.; ARRUETA, C. (Comp.). La comunicación digital. Redes sociales, nuevas audiencias y convergencia: desafíos y oportunidades para la industria, el Estado y los usuarios. Ediunju/Fadeccos, 2017. p. 165-174.

ARUGUETE, Natalia. The agenda setting hypothesis in the new media environment. Comunicación y Sociedad, v. 28, p.35-58, 2017.

BARBERÁ, Pablo. Birds of the Same Feather Tuit Together. Bayesian Ideal Point Estimation Using Twitter Data. Political Analysis, v. 23, n. 1, p.76-91, 2015.

BARBERÁ, Pablo; JOST, John ; NAGLER, Jonathan; TUCKER, Joshua; BONNEAU, Richard. Tweeting From Left to Right. Psychological Science, v. 26, n. 10, p.1531-1542, 2015.

BAUM, Mathew A.; GROELING, Tim. New Media and the Polarization of American Political Discourse. Political Communication, v. 25, n. 4, p.345-365, 2008. 
EID\&A - Revista Eletrônica de Estudos Integrados em Discurso e Argumentação, Ilhéus, n. 16 esp. "Discurso e argumentação na política latino-americana, set.2018.

BENNETT, Lance; IYENGAR, Shanto. A New Era of Minimal Effects? The Changing Foundations of Political Communication, 2008.

BIZER, George Y.; TORMALA, L. Zakary; RUCKER, D. Derec; PETTY, E. Richard. Memory-based versus on-line processing: Implications for attitude strength. Journal of Experimental Social Psychology, v. 42, n. 5, p.646-653, 2006.

BOCZKOWSKI, Pablo; MITCHELSTEIN, Eugênia; MATASSI, Mora. Incidental News: How Young People Consume News on Social Media. Paper presented at the Proceedings of the 50th Hawaii International Conference on System Sciences, 2017.

BOUTET, Antoine; HYOUNGSHICK, Kim; EIKO, Y. et al. What's in Your Tweets? I KnowWho You Supported in the UK 2010 General Election. Proc. Sixth International AAAI Conference onWeblogs and SocialMedia, 2012.

BRUNS, Axel. Blogs, Wikipedia, Second Life and beyond: From production to produsage. New York: Peter Lang, 2008.

CALVO, Ernesto. Anatomía política de Twitter en Argentina. Tuiteando \#Nisman. Buenos Aires: Capital Intelectual, 2015.

CALVO, Ernesto. ¿Cómo sigue la cosa? El Estadista, 2017. Disponível em: http://elestadista.com.ar/?p=13455. Acesso em: 6 nov. 2017.

CHAFFEE, Steven H.; METZGER, Miriam J. The end of mass communication? Mass communication \& society, v.4, n.4, p.365-379, 2001.

FESTINGER, Leon. A theory of cognitive dissonance. Stanford University Press, 1962.

GANE, Nicholas; BEER, David. New media. New York: Berg, 2008.

HABERMAS, Jurgen. Teoría de la acción comunicativa. I: Racionalidad de la acción y racionalización social. Madrid: Taurus, 2002.

HALL, Royal; ARTWICK, Claudete. Body found on Twitter: The role of alternative sources in social media agenda setting. International Communication Association Conference. Sheraton Phoenix Downtown, Phoenix, AZ: International Communication Association, 2012. p.1-29.

ISAÍA, Walter; ARUGUETE, Natalia. Santiago Maldonado: la disputa por el sentido. Página/12. 2017. Disponível em https://www.pagina12.com.ar/65424-santiagomaldonado-la-disputa-por-el-sentido. Acesso em: 6 nov. 2017.

KEY, V. O. Jr.; CUMMINGS, Milton. The responsible electorate. Belknap Press of Harvard University Press, 1966.

KUSHIN, Matthew J. Tweeting the Issues in the Age of Social Media? Intermedia Agenda Setting Between The New York Times and Twitter. Washington State University, 2010. 
EID\&A - Revista Eletrônica de Estudos Integrados em Discurso e Argumentação, Ilhéus, n. 16 esp. "Discurso e argumentação na política latino-americana, set.2018.

LASORSA, Dominic L.; LEWIS, Seth C.; HOLTON, Avery E. Normalizing Twitter: Journalism Practice in an Emerging Space. Journalism Studies, v. 13, n. 1, p. 19-36, 2012.

LAZARSFELD, Paul; BERELSON, Bernard; GAUDET, Hazel. The People's Choice. How de Voter Makes Up His Mind in the Presidential Campaign. New York: Columbia University Press, 1944.

MCCOMBS, Maxwell. La comunicación de masas en las campañas políticas: información, gratificación y persuación. In: MORAGAS, M. de (Ed.). Sociología de la comunicación de masas. Barcelona: Gustavo Gili, 1993. p. 95-121.

PARISIER, Eli. El filtro burbuja. Cómo la red decide lo que leemos y lo que pensamos. Buenos Aires: Taurus, 2017.

SHAW, Donald; MCCOMBS, Maxwell; WEAVER, David; HAMM, Bradley. Individuals, Groups, and Agenda Melding: A Theory of Social Dissonance. International Journal of Public Opinion Research, v. 11, n. 1, p.2-24, 1999.

SINGER, Jane B. The political j-blogger Normalizing a new media form to fit old norms and practices. Journalism, v. 6, n.2, p. 173-198, 2005.

SCHULTZ, Tanjev. Mass media and the concept of interactivity: an exploratory study of online forums and reader email. Media Culture Society, v. 22, n. 2, p. 205-221, 2000.

WEBSTER, James G.; KSIAZEK, Thomas B. The Dynamics of Audience Fragmentation: Public Attention in an Age of Digital Media. Journal of Communication, v. 62, n. 1, p.39-56, 2012.

Tradução:

Fernando Raposo

Graduando em Letras pela Universidade Federal da Integração Latino-Americana

Gracineia Araújo dos Santos

Docente da Universidade Federal da Integração Latino-Americana

Forma de citação sugerida:

ARUGUETE, Natalia; CALVO, Ernesto. Redes sociais e política na Argentina. Trad. Fernando Raposo e Gracineia Araújo dos Santos. EID\&A - Revista Eletrônica de Estudos Integrados em Discurso e Argumentação, Ilhéus, n. 16 esp. "Discurso e argumentação na política latino-americana", p. 299-313, set.2018.

Recebido em: 25/07/2018

Aprovado em: $26 / 08 / 2018$ 